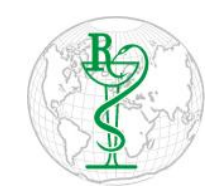

INDO GLOBAL JOURNAL OF

PHARMACEUTICAL SCIENCES

ISSN 2249- 1023

\title{
Re-infection and Immunological Effect of Corona Virus: A Detailed Review
}

\author{
Nimesh Singh ${ }^{1 *}$, Sandeep Shukla ${ }^{2}$, Archna Pandey $^{2}$ \\ ${ }^{1}$ Flax Laboratories, B-29/1, Mahad MIDC, Taluka-Mahad, Distt. - Raigad, M.H., INDIA \\ ${ }^{2}$ Department of Chemistry, Dr. H.S. Gour University, Sagar, M.P. INDIA
}

Address for Correspondence: Nimesh Singh, nimsonlab@gmail.com

\begin{abstract}
Received:
06.05.2020

Accepted:

12.05.2020

Published:

23.08.2020

Keywords

Reinfection,

COVID-19,

SARS-CoV-2,

Cytokine,

Immune

response.
\end{abstract}

\begin{abstract}
As the world is seeing the plague of COVID-19, an illness brought about by a novel coronavirus, SARS-CoV-2, developing hereditary qualities and clinical confirmations recommend a comparative way to those of SARS and MERS. Most coronaviruses aren't perilous. COVID-19 is an illness that can cause what specialists call a respiratory tract disease. It can influence your upper respiratory tract (sinuses, nose, and throat) or lower respiratory tract (windpipe and lungs). SARS-CoV-2 is able to stay undetected longer than many flu or coronaviruses and its spike proteins are able to gain entry by unlocking the ACE2 protein on the lung cells. Once in, they hijack the cell's machinery, replicate and multiply and infect adjoining cells. Like the defining ACE2 proteins on the epithelial cells, viruses too have a tell-tale signature on their surface called antigens and spotting these is what kicks the immune system into action by producing antibodies. (C) 2020 iGlobal Research and Publishing Foundation. All rights reserved.
\end{abstract}

Cite this article as: Singh, N.; Shukla, S.; Pandey, A. Re-infection and immunological effect of corona virus: a detailed review. Indo Global J. $\quad$ Pharm. $\quad$ Sci., $\quad 2020 ; \quad 10(2): \quad 1-7 . \quad$ DOI:
http://doi.org/10.35652/IGJPS.2020.10201.

\section{INTRODUCTION}

The world encountered the episodes of coronavirus contamination that undermine worldwide pandemic in 20022003 by Severe Acute Respiratory Syndrome (SARS) and in 2011 by Middle East Respiratory Syndrome (MERS). In the two cases, the causative specialists (SARS-CoV and MERS$\mathrm{CoV}$, separately) were recently recognized coronavirus in the class Betacoronavirus with zoonotic starting point. Toward the finish of 2019, episode of another coronavirus that causes respiratory-related ailment was accounted for in Wuhan, Hubei, China, a sickness presently authoritatively called "the Corona Virus Disease 2019; COVID-19". The coronavirus that is the causative operator of this respiratory malady was distinguished and its genome is completely sequenced [1].

Over a long time since the episode of the 1918 flu pandemic, we presently appear to confront another pandemic. The episode of the new coronavirus (SARS$\mathrm{CoV}-2$ ) disease is spreading to each mainland, compelling us to live with this infection for may be quite a while. Researchers and clinicians have learned a lot of coronavirus sickness 2019, COVID-19, and its pathogenesis [2]: not all individuals presented to SARS-CoV-2 are contaminated and not every single tainted patient create serious respiratory ailment. In like manner, SARS-CoV-2 disease can be generally isolated into three phases:

Stage I, an asymptomatic brooding period with or without distinguishable infection;

Stage II, non-serious indicative period with the nearness of infection;

Stage III, extreme respiratory suggestive stage with high popular burden [3].

From the perspective of counteraction, people at stage I, the secrecy bearers, are the least reasonable on the grounds that, in any event on certain events, they spread the infection unconsciously: in reality, the main asymptomatic transmission has been accounted for in Germany [4]. The 
Indo Global Journal of Pharmaceutical Sciences, 2020; 10(2): 1-7

job of asymptomatic SARS-CoV-2 tainted people in spreading the disease stays to be characterized.

Up to 10 percent of coronavirus patients leaving clinical offices in Wuhan in the wake of being tried negative for Covid-19 appear to have along these lines been recontaminated, as per the South China Morning Post. This isn't the first occasion when that there have been reports of re-disease. Specialists in Wuhan are confounded. Social insurance laborers in this focal Chinese city where the coronavirus first developed have watched a few occasions wherein patients have left emergency clinic with no residual hints of the infection in their bodies and afterward tried positive for the coronavirus a second time.[5] A spate of baffling second-time diseases is raising doubt about the precision of COVID-19 indicative instruments even as China gets ready to lift isolate measures to permit occupants to leave the focal point of its flare-up one month from now. It's additionally raising worries of a potential second rush of cases.

From March 18-22, the Chinese city of Wuhan detailed no new instances of the infection through household transmission - that is, contamination given starting with one individual then onto the next. The accomplishment was viewed as a defining moment in endeavors to contain the infection, which has tainted in excess of 80,000 individuals in China. Wuhan was especially hard-hit, with the greater part of every affirmed case in the nation. [6] The coronavirus might be "reactivating" in individuals who have been restored of the sickness, as per Korea's Centers for Disease Control and Prevention. About 51 patients classed as having been relieved in South Korea have tried positive once more, the CDC said in a preparation on Monday. Instead of being tainted once more, the infection may have been reactivated in these individuals, given they tried positive again not long after being discharged from isolate, said Jeong Eun-kyeong, executive general of the Korean CDC. $[7,8]$

When a re-infection (Fig. 1), occurs with the same virus, the immune system is able to rapidly respond, as immune memory occurs. Viral replication is suppressed more quickly than with a primary infection, and levels do not usually become significant. Symptoms are often absent and, if they occur, they are usually much milder than with a primary infection. It should be noted that with some acute infections, such as influenza, one strain may not provide optimal immunity against another strain, and re-infections may present in the way primary infections do. The extent to which the immune response to one virus is protective against a related virus and the extent to which immune memory is able to prevent symptoms with a re-infection both depend on the virus in question. In some cases, re-infection with a related strain leads to worsening of symptoms, or different symptomatology, such as with Dengue virus infection, where immunity to one strain enables the replication of other strains via uptake into monocytes; the virus therefore replicates by antibody-mediated enhancement of infection. It is in cases such as these that Dengue haemorrhagic fever and Dengue shock syndrome occur. [14]

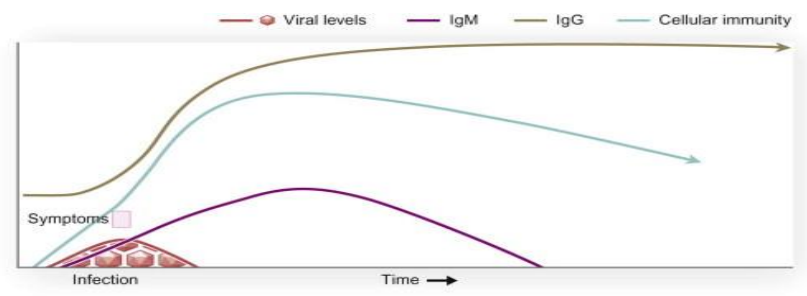

Fig. 1. Acute infection - secondary infection [23]

\section{Two Phase Immune Response Induced by Covid-19 Infection}

Clinically, the insusceptible reactions instigated by SARSCoV-2 disease are two staged. During the brooding and nonserious stages, a particular versatile invulnerable reaction is required to take out the infection and to block malady movement to extreme stages. Accordingly, techniques to support invulnerable reactions (against sera or pegylated IFN $\alpha$ ) at this stage are surely significant. For the advancement of an endogenous defensive invulnerable reaction at the hatching and non-serious stages, the host ought to be in acceptable general wellbeing and a proper hereditary. Foundation (for example HLA) that inspires explicit antiviral resistance. Hereditary contrasts are notable to add to singular varieties in the resistant reaction to pathogens. In any case, when a defensive invulnerable reaction is disabled, infection will proliferate and enormous obliteration of the influenced tissues will happen, particularly in organs that have high ACE2 articulation, for example, digestive tract and kidney. The harmed cells prompt intrinsic irritation in the lungs that is to a great extent intervened by expert fiery macrophages and granulocytes. Lung irritation is the fundamental driver of hazardous respiratory issue at the extreme stage [14].

\section{Cytokine tempest and lung harm}

The cytokine discharge disorder (CRS) appears to influence patients with extreme conditions. Since lymphocytopenia is regularly observed in extreme COVID-19 patients, the CRS brought about by SARS-CoV-2 infection must be intervened by leukocytes other than T cells, as in patients getting CAR-T 


\section{Indo Global Journal of Pharmaceutical Sciences, 2020; 10(2): 1-7}

treatment; a high WBC-check is normal, proposing it, in relationship with lymphocytopenia, as a differential indicative model for COVID-19. Regardless, blocking IL-6 might be successful. Blocking IL-1 and TNF may likewise profit patients. Albeit different clinical locales in China have reported the utilization of mesenchymal stromal/undifferentiated cells (MSCs) in serious cases with COVID-19 disease, strong outcomes still can't seem to be seen. One proviso is that MSCs should be actuated by IFN $\gamma$ to apply their mitigating impacts, which might be missing in seriously influenced patients as $\mathrm{T}$ cells are not very much enacted by SARS-CoV-2 contamination. To upgrade adequacy, one could consider utilizing the "permitting approach": pretreat MSCs with IFN $\gamma$ with/without TNF or IL-1 [14].

\section{HLA haplotypes and SARS-CoV-2 contamination}

The major-histocompatibility-complex antigen loci (HLA) are the prototypical contender for hereditary helplessness to irresistible illnesses $[9, \quad 10]$. Haplotype HLA-loci changeability results from particular weight during codevelopment with pathogens. Immunologists have discovered that $\mathrm{T}$-cell antigen receptors, on CD4+ or CD8+ $\mathrm{T}$ cells perceive the conformational structure of the antigen-restricting woods together with the related antigen peptides. In this manner, diverse HLA haplotypes are related with unmistakable infection susceptibilities. The collection of the HLA particles creating a haplotype decides the endurance during advancement. [14] (Fig. 2)

\section{Hyaluronan: a potential reason for fatalities}

The intrinsic invulnerable reaction to tissue harm brought about by the infection could prompt intense respiratory pain disorder (ARDS), in which respiratory disappointment is described by the fast beginning of far reaching aggravation in the lungs and ensuing casualty [13]. The side effects of ARDS patients incorporate short/quick breathing, and cyanosis. Extreme patients admitted to serious consideration units frequently require mechanical ventilators and those incapable to inhale must be associated with extracorporeal layer oxygenation (ECMO) to help life [11]. CT pictures uncovered that there are trademark white patches called "ground glass", containing liquid in the lungs [12]. Late post-mortem examinations have affirmed that the lungs are loaded up with clear fluid jam, much looking like the lungs of wet suffocating [13]. In spite of the fact that the idea of the unmistakable jam still can't seem to be resolved, hyaluronan (HA) is related with ARDS [9]; in addition, during SARS disease, the creation and guideline of hyaluronan is inadequate.

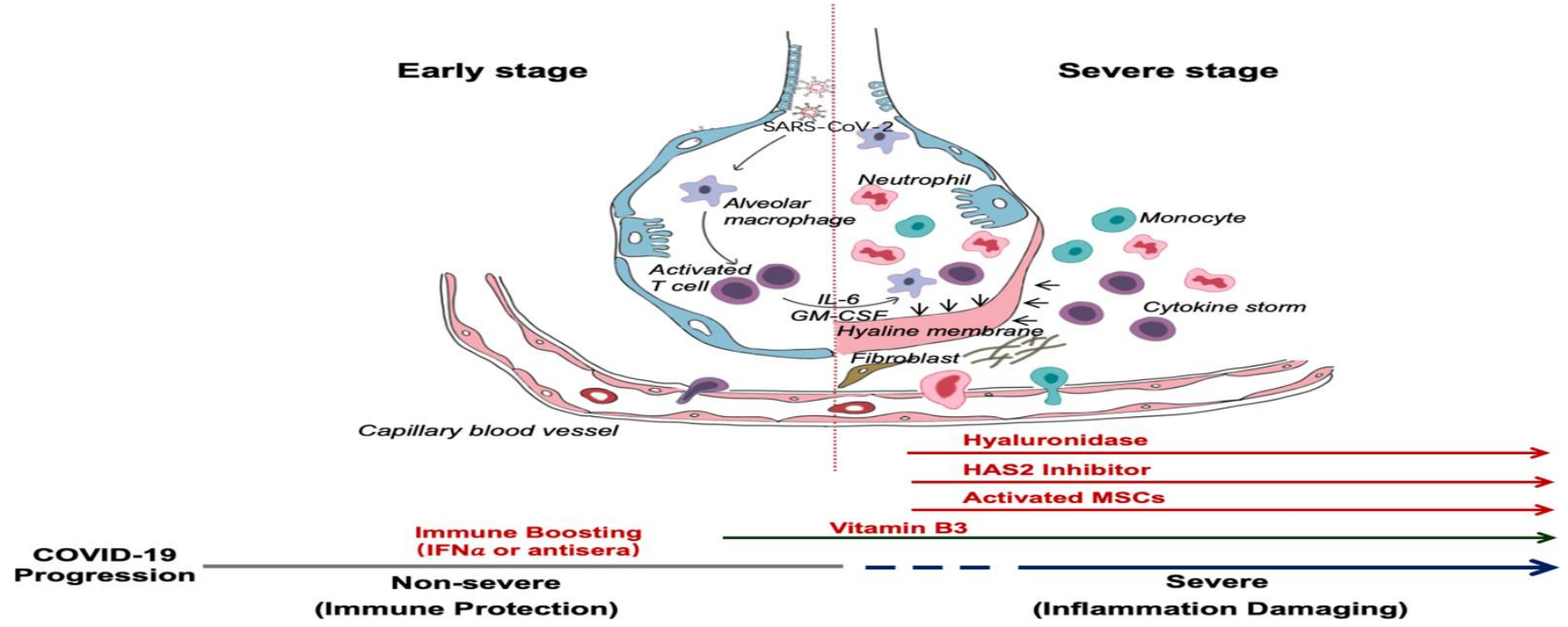

Fig. 2. After an incubation period, the invading COVID-19 virus causes non-severe symptoms and elicits protective immune responses. The successful elimination of the infection relies on the health status and the HLA haplotype of the infected individual. In this period, strategies to boost immune response can be applied. If the general health status and the HLA haplotype of the infected individual do not eliminate the virus, the patient then enters the severe stage, when strong damaging inflammatory response occurs, especially in the lungs. At this stage, inhibition of hyaluronan synthase and elimination of hyaluronan can be prescribed. Cytokine activated mesenchymal stem cells can be used to block inflammation and promote tissue reparation. Vitamin B3 can be given to patients starting to have lung CT image abnormalities. [20] 


\section{Indo Global Journal of Pharmaceutical Sciences, 2020; 10(2): 1-7}

Intrinsic Immune Responses to SARS-CoV-2 Infection

Gaining Insight from Strategies utilized by SARS-CoV and MERS-CoV:

Presently, just constrained data is accessible on the host natural invulnerable status of SARS-CoV-2 tainted patients. In one report where 99 cases in Wuhan were researched, expanded complete neutrophils (38\%), decreased absolute lymphocytes (35\%), expanded serum IL-6 (52\%) and expanded c-receptive protein $(84 \%)$ were observed. [12]

Viable natural safe reaction against viral contamination depends intensely on the interferon (IFN) type I reactions and its downstream course that finishes in controlling viral replication and acceptance of successful versatile resistant reaction. While SARS-CoV and SARS-CoV-2 appear to share the section receptor of ACE2, MERS-CoV utilizes dipeptidyl peptidase (DPP)- 4 as a particular receptor.[15] The putative receptor of SARS-CoV-2, ACE2, is for the most part communicated in a little subset of cells in the lung called type 2 alveolar cells.[16] It has been accounted for that SARS-Co$\mathrm{V}$ legitimately contaminates macrophages and $\mathrm{T}$ cells, a key element in SARS-CoV-interceded pathogenesis.[17] Whether SARS-CoV-2 taints any resistant cells are as yet obscure. Just negligible rates of monocytes/macrophages in the lung communicated ACE2.26 If ACE2 is insignificantly communicated in the potential objective invulnerable cells, it is conceivable that different receptors may exist, or other cell passage mode is used, for example, counter acting agent subordinate upgrade (Fig. 3).

1. Until an immunization is accessible, our insusceptible frameworks should adjust independent to COVID-19.

2. The insusceptible framework is the body's staggered safeguard arrange against possibly hurtful microscopic organisms, infections and different life forms.

3. A sound way of life causes one's safe framework to be in the most ideal shape to handle pathogens, however it's smarter to stop them entering the body in any case.

The coronavirus pandemic has directed the world's concentration toward the resistant framework, the body's protection power against illness causing microscopic organisms, infections and different life forms that we contact, ingest and breathe in consistently. Consider it the body's very own military working from the cell to large scale level. Every cell, particle, tissue and organ in this military assumes a crucial job in warding off attacking pathogens, and furthermore helps guard against inside dangers like malignant growth.

The system has two types of response: innate and adaptive. (Fig. 4)

The body's natural barriers against disease-causing intruders for example, our skin, the mucous and hairs in our nose, and the acid in our stomachs - are part of our innate immune systems.

Adaptive immunity develops over a lifetime of contact with pathogens and vaccines, preparations which help our immune systems to distinguish friend from foe.

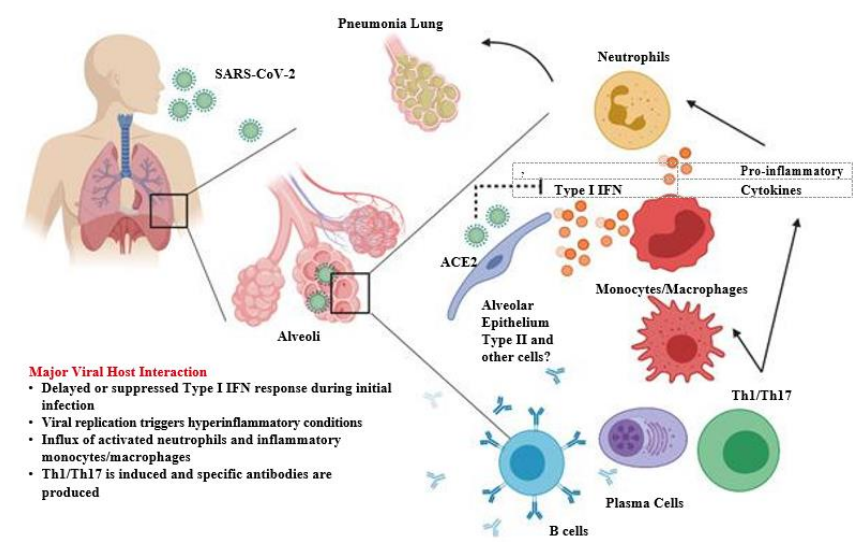

Figure 3. Proposed host immune responses during SARS-CoV-2 infection. Aerosolized uptake of SARS-CoV-2 leads to infection of ACE2 expressing target cells such as alveolar type 2 cells or other unknown target cells. Virus may dampen anti-viral IFN responses resulting in uncontrolled viral replication. The influx of neutrophils and monocytes/macrophages results in hyperproduction of proinflammatory cytokines. The immunopathology of lung may be the result of the "cytokine storms". Specific Th1/Th17 may be activated and contributes to exacerbate inflammatory responses. B cells/plasma cells produce SARS-CoV-2 specific antibodies that may help neutralize viruses. The question marks indicated events that are still speculative or unknown. Figure is made with biorender (https://biorender.com/) [15] 


\section{Indo Global Journal of Pharmaceutical Sciences, 2020; 10(2): 1-7}

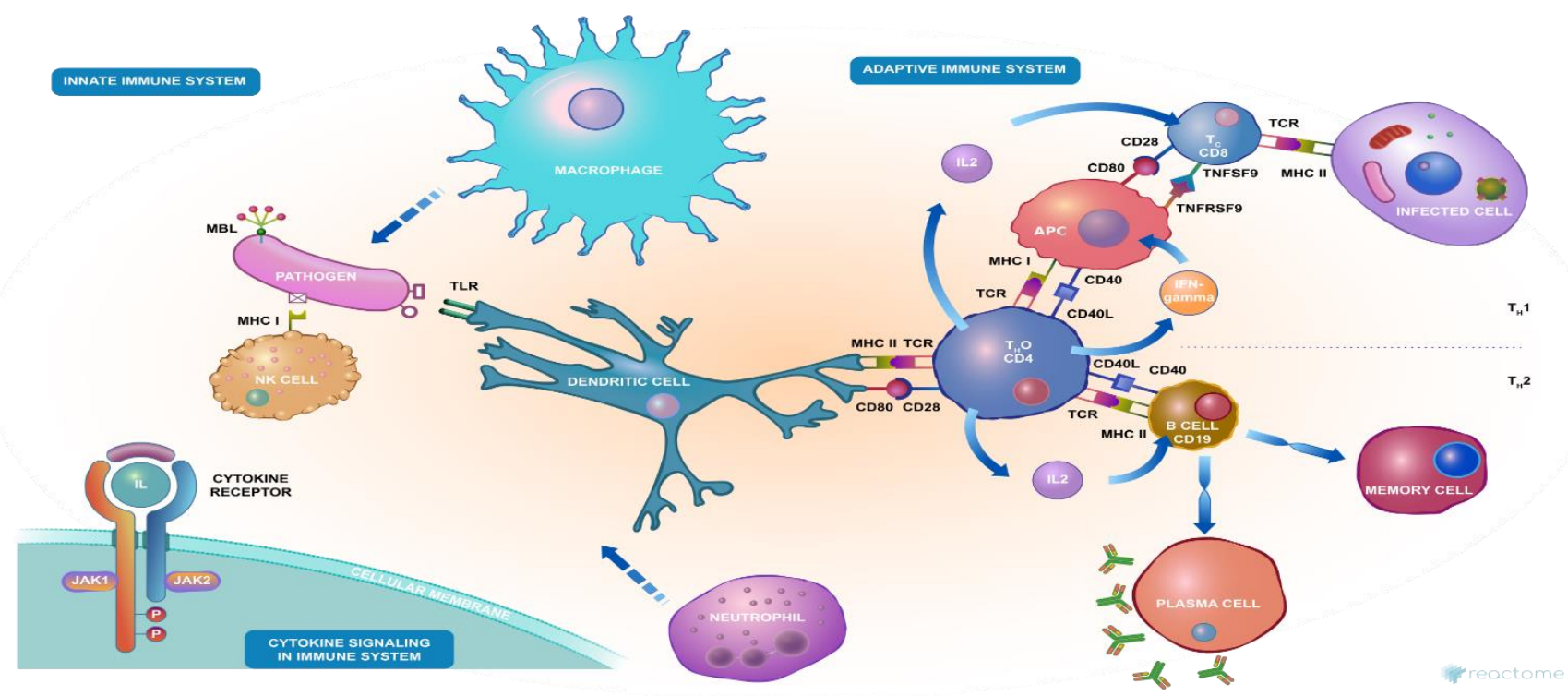

Fig 4.Humans are exposed to millions of potential pathogens daily, through contact, ingestion, and inhalation. Our ability to avoid infection depends on the adaptive immune system and during the first critical hours and days of exposure to a new pathogen, our innate immune system. Vaccination safely teaches our adaptive immune systems to repel a wide range of diseases, and thus protect ourselves and others. There is currently no vaccine for coronavirus, and we may not see one for 18 months or longer. So, for now, our immune systems must adapt unaided to this potentially deadly threat. [21]

Would you be able to get re-tainted in the wake of recuperating from COVID-19?

There are a great deal of vulnerability, yet specialists TIME talked with state that it's conceivable the reports of patients who appeared to have recuperated yet then tried positive again were not instances of re-contamination, yet were situations where waiting disease was not identified by tests for a while. Specialists state the body's immune response reaction, activated by the beginning of an infection, implies it is impossible that patients who have recuperated from COVID19 can get re-tainted so not long after getting the infection. Antibodies are regularly delivered in a patient's body around seven to 10 days after the underlying beginning of an infection, says Vineet Menachery, a virologist at the University of Texas Medical Branch [18].

\section{Could the infection be 'reactivated' after you recuperate?}

In declaring that recuperated patients were re-trying positive, South Korea's Centers for Disease Control and Prevention (KCDC) offered another hypothesis: that the infection could have been "reactivated."

Be that as it may, specialists are progressively wary. Goodness Myoung-wear, an educator of inward medication at Seoul National University and an individual from the WHO's Strategic and Technical Advisory Group for Infectious Hazards, says the most conceivable clarification is that the tests got waiting viral hereditary material, as opposed to reemergent contamination. "Significantly after the infection is dead, the nucleic corrosive (RNA) sections despite everything stay in the cells," says Oh. He says reactivation of the infection isn't as likely. In South Korea, patients must test negative in two tests inside 24 hours before they are discharged from isolate [18].

Does recuperating from COVID-19 make you invulnerable?

There hasn't been sufficient opportunity to examine COVID19 so as to decide if patients who recuperate from COVID-19 are insusceptible to the infection - and provided that this is true, to what extent the insusceptibility will last. Be that as it may, starter examines give a few insights. For instance, one examination directed by Chinese specialists (which has not yet been peer-investigated) found that antibodies in rhesus monkeys kept primates that had recouped from COVID-19 from turning out to be tainted again upon presentation to the infection [18].

\section{How your body mounts a reaction:}

At the point when your body distinguishes a remote trespasser like SARS-CoV-2, the new coronavirus that causes COVID19 , your resistant framework rapidly triggers a progression of reactions to attempt to recognize and expel it.

The principal line of barrier is what's known as the intrinsic safe reaction, which is adequately "an amping up" of the 


\section{Indo Global Journal of Pharmaceutical Sciences, 2020; 10(2): 1-7}

insusceptible framework, said Dr Labzin. "We will in general consider it the vague reaction ... ready to react to whatever's attacking and introducing a risk to the body," Dr Labzin said. The inborn insusceptible reaction for the most part assists with hindering the disease before the versatile resistant reaction kicks in, which comprises of antibodies made by B-cells and antiviral cell-slaughtering T-cells. Outfitted with more data about the disease - including the novel proteins found on the infection's surface called antigens - the body produces Tcells that go looking for contaminated cells and execute them.

To target and demolish the disease, the insusceptible framework refines this counter acting agent into a subsequent sort called immunoglobulin $\mathrm{G}$, or IgG, which can explicitly perceive and kill the infection, and stop it entering new cells. It ordinarily takes possibly 14 days for these antibodies to show up. Little, fundamental examinations in creatures propose COVID-19 invulnerability stays for half a month in any event.

In any case, at that point an ongoing investigation of 175 recouped coronavirus patients in Shanghai - which has additionally not yet been peer-looked into - discovered almost $33 \%$ of individuals had suddenly low degrees of killing antibodies, and ten individuals had no discernible follows at all [19].

\section{CONCLUSION}

Health officials in some countries have said they've seen examples of people recovering from Covid-19 only to test positive for the virus again — what they've taken to calling "reactivation," to differentiate it from a second infection. But experts are skeptical that either is occurring. While no possibility can be eliminated at this early stage of the outbreak, they say that there are more likely explanations for a positive diagnostic test coming after a negative test. For one: The tests used to diagnose Covid-19 look for snippets of the virus' genome, its RNA. But what they can't tell you is if what they're finding is evidence of "live" virus, meaning infectious virus. Once a person fights off a virus, viral particles tend to linger for some time. These cannot cause infections, but they can trigger a positive test. The levels of these particles can fluctuate, which explains how a test could come back positive after a negative test. But it does not mean the virus has become active, or infectious, again. And two: the diagnostic tests typically rely on patient samples pulled from way back in their nasal passages.

The development of immunity to a pathogen through natural infection is a multi-step process that typically takes place over 1-2 weeks (Fig.-5). The body responds to a viral infection immediately with a non-specific innate response in which macrophages, neutrophils, and dendritic cells slow the progress of virus and may even prevent it from causing symptoms. This non-specific response is followed by an adaptive response where the body makes antibodies that specifically bind to the virus. These antibodies are proteins called immunoglobulins. The body also makes T-cells that recognize and eliminate other cells infected with the virus. This is called cellular immunity. This combined adaptive response may clear the virus from the body, and if the response is strong enough, may prevent progression to severe illness or re-infection by the same virus. This process is often measured by the presence of antibodies in blood. WHO continues to review the evidence on antibody responses to SARS-CoV-2 infection.2-17 Most of these studies show that people who have recovered from infection have antibodies to the virus. However, some of these people have very low levels of neutralizing antibodies in their blood,4 suggesting that cellular immunity may also be critical for recovery. As of 24 April 2020, no study has evaluated whether the presence of antibodies to SARS-CoV-2 confers immunity to subsequent infection by this virus in humans.

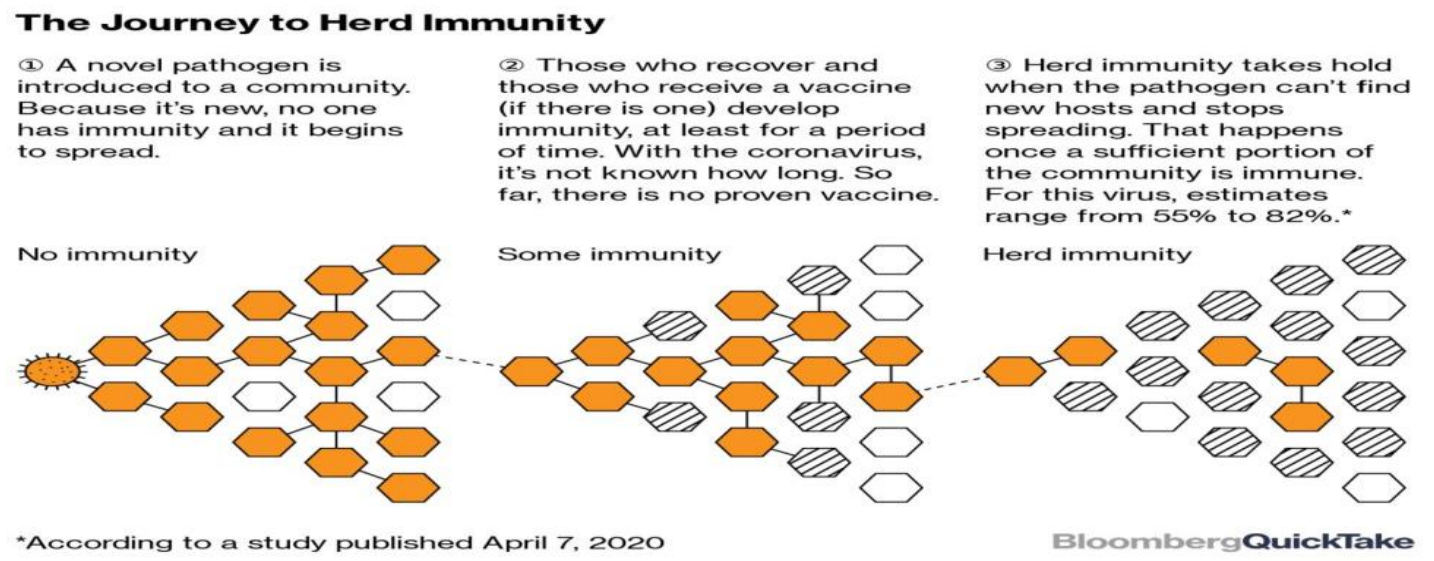

Fig 5. The journey of herd immunity [22] 
Indo Global Journal of Pharmaceutical Sciences, 2020; 10(2): 1-7

\section{CONFLICT OF INTEREST}

The authors confirm that this article content has no conflict of interest.

\section{ACKNOWLEDGEMENT}

Nil

\section{REFERENCES}

1. Wu F, Zhao S, Yu B, Chen YM, Wang W, Song ZG, et al. A new coronavirus associated with human respiratory disease in China. Nature [Preprint]. 2020 [cited 2020 Feb 16]: [19 p.]. Available from: https://doi.org/10.1038/ s41586-020-2008-3

2. Guan WJ, Ni ZY, Hu Y, Liang WH, Ou CQ, He JX, et al. Clinical Characteristics of Coronavirus Disease 2019 in China. The New England journal of medicine.

3. Wang $\mathrm{D}, \mathrm{Hu} \mathrm{B}, \mathrm{Hu} \mathrm{C}$, Zhu F, Liu X, Zhang J, et al. Clinical Characteristics of 138 Hospitalized Patients With 2019 Novel Coronavirus-Infected Pneumonia in Wuhan, China. Jama.

4. Rothe C, Schunk M, Sothmann P, Bretzel G, Froeschl G, Wallrauch C, et al. Transmission of 2019-nCoV Infection from an Asymptomatic Contact in Germany. The New England journal of medicine. 2020;382:970-1

5. "India Suspends All Tourist Visas Till April 15 Over Coronavirus: 10 Facts". NDTV.com. Retrieved 12 March 2020.

6. https://www.france24.com/en/20200328-can-the-coronavirus-infectsomeone-twice

7. https://www.npr.org/sections/goatsandsoda/2020/03/27/822407626/myst ery-in-wuhan-recovered-coronavirus-patients-test-negative-then-positive

8. https://fortune.com/2020/04/09/coronavirus-reinfection-fears-growcured-patients-test-positive-reactivated-virus/

9. Blackwell JM, Jamieson SE, Burgner D. HLA and infectious diseases. Clin Microbiol Rev. 2009;22:370-85.

10. Matzaraki V, Kumar V, Wijmenga C, Zhernakova A. The MHC locus and genetic susceptibility to autoimmune and infectious diseases. Genome Biol. 2017;18:76.

11. MacLaren G, Fisher D, Brodie D. Preparing for the most critically Ill patients with COVID-19: the potential role of extracorporeal membrane oxygenation. JAMA. 2020.

12. Hallgren R, Samuelsson T, Laurent TC, Modig J. Accumulation of hyaluronan (hyaluronic acid) in the lung in adult respiratory distress syndrome. Am Rev Respir Dis. 1989;139:682-7.

13. Xu Z, Shi L, Wang Y, Zhang J, Huang L, Zhang C, et al. Pathological findings of COVID-19 associated with acute respiratory distress syndrome. The Lancet Respiratory medicine. 2020.

14. Wang Y, Chen X, Cao W, Shi Y. Plasticity of mesenchymal stem cells in immunomodulation: pathological and therapeutic implications. Nat Immunol. 2014; 15:1009-16.

15. Zhou P, Yang XL, Wang XG, Hu B, Zhang L, Zhang W, et al. A pneumonia outbreak associated with a new coronavirus of probable bat origin. Nature [Preprint]. 2020 [cited 2020 Feb 15]: [15 p.]. Available from: https://doi. org/10.1038/s41586-020-2012-7

16. Zhu N, Zhang D, Wang W, Li X, Yang B, Song J, et al. A Novel Coronavirus from Patients with Pneumonia in China, 2019. N Engl J Med. 2020; 382(8):727-33.

17. Perlman S, Dandekar AA. Immunopathogenesis of coronavirus infections: implications for SARS. Nat Rev Immunol. 2005;5(12):917-27

18. https://time.com/5810454/coronavirus-immunity-reinfection/

19. https://www.abc.net.au/news/health/2020-04-20/coronavirus-covid-19immunity-reinfection-what-we-know-so-far/12163778

20. Yufang Shi, Ying Wang, Changshun Shao, Jianan Huang, Jianhe Gan, Xiaoping Huang, Enrico Bucci, Mauro Piacentini, Giuseppe Ippolito \& Gerry Melino COVID-19 infection: the perspectives on immune responses, Cell Death \& Differentiation volume 27, pages14511454(2020)

21. https://reactome.org/content/detail/R-HSA-168256

22. How Herd Immunity Works, a Possible Key to the Covid Pandemic's End By Lisa Beyer and Shawn Hasto April 14, 2020, Quick take.

23. Stephen N.J. Korsman MMed FCPath, ... Wolfgang Preiser MRCPath, in Virology, 2012 